\title{
Studies in microgravity, simulated microgravity and gravity do not support a gravitostat
}

\author{
Russell T Turner ${ }^{1,2}$, Adam J Branscum³, Carmen P Wong ${ }^{1}$, Urszula T Iwaniec ${ }^{1,2}$ and Emily Morey-Holton ${ }^{4}$ \\ 1Skeletal Biology Laboratory, School of Biological and Population Health Sciences, Oregon State University, Corvallis, Oregon, USA \\ ${ }^{2}$ Center for Healthy Aging Research, Oregon State University, Corvallis, Oregon, USA \\ ${ }^{3}$ Biostatistics Program, School of Biological and Population Health Sciences, Oregon State University, Corvallis, Oregon, USA \\ ${ }^{4}$ Life Science Division, NASA Ames Research Center, Moffett Field, California, USA
}

Correspondence should be addressed to R T Turner: russell.turner@oregonstate.edu

\begin{abstract}
The gravitostat is purported to function as a leptin-independent, osteocyte-dependent mechanism for regulation of energy balance. If correct, reduced activation of gravitostat signaling caused by prolonged sitting may contribute to obesity. The gravitostat concept is supported by reduced body mass in rodents following surgical implantation of weighted capsules. However, the procedure induces a confounding injury response. We, therefore, sought to confirm a gravitostat by decreasing (microgravity and simulated microgravity) or increasing (simulated gravity) weight using less invasive models (spaceflight, hindlimb unloading and centrifugation). We also evaluated changes in weight following non-surgical injury (radiation). Male rats (Wistar, Sprague-Dawley and Fischer 344) ranging in age from 5-12 weeks at launch and flown for 4-19 days in low Earth orbit exhibited slightly lower (4-day flight) or no difference (all other studies) in weight compared to ground controls. Rats subjected to inflight $(1.0 \mathrm{G})$ or ground $(1.04 \mathrm{G}$ and $1.56 \mathrm{G}$ ) centrifugation during a 19-day mission did not differ in weight. In female rats (Fischer 344), spaceflight (14 days) did not alter ovariectomy-induced weight gain. Finally, hindlimb unloading resulted in weight loss in lean and obese mice. The aforementioned findings are inconsistent with outcomes predicted by a gravitostat namely increased mass during weightlessness and decreased mass when subjected to $>1 \mathrm{G}$ simulated gravity. Injury (dose-associated graded increases in radiation) mimicked the leptinindependent weight changes attributed to a gravitostat. Taken together, these findings do not support gravitostat regulation of energy balance and suggest injury/stress as an alternative mechanism for weight loss induced by weighted capsules.
\end{abstract}

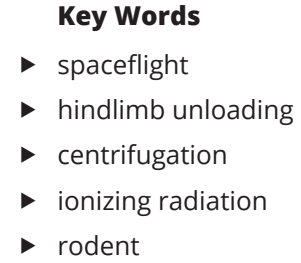

Journal of Endocrinology (2020) 247, 273-282

\section{Introduction}

Obesity is a serious public health concern in developed countries and is an emerging concern in developing countries (Inoue et al. 2018). The biological basis for excessive weight gain is straightforward, energy intake exceeds energy expenditure, but the societal underpinnings contributing to the weight gain phenomena are hotly debated (Stanhope 2016, Forouhi et al. 2018). Some epidemiological studies have identified positive associations between duration of sitting and risk for obesity (Levine et al. 2005, Chau et al. 2012). Based on this association, Jansson et al. (2018) hypothesized that a leptin-independent osteocyte-dependent homeostat (gravitostat) in the lower extremities detects weight and regulates appetite. Rodent studies performed by Jansson 
et al. (2018) provide experimental support for the proposed mechanism. Specifically, insertion of capsules equivalent to $15 \%$ of body mass into abdominal cavities of mice and rats reduced body mass and this reduction did not occur in mice depleted in osteocytes.

Osteocytes are favorably positioned to respond to changes in weight and these terminally differentiated bone cells play a fundamental role in signal transduction pathways that regulate bone mass and architecture in response to mechanical loading (Bonewald \& Johnson 2008). Known as the mechanostat, this pathway regulates bone turnover balance in response to changes in peak levels of mechanical strain perceived by osteocytes (Frost 1987) and thereby functions as an adaptive mechanism to optimize bone mass and architecture in response to mechanical signals (Iwaniec \& Turner 2016). The novel hypothesis that mechanical signaling induced by body weight also plays a role in regulating energy homeostasis provides a mechanistic basis for a positive association between time spent sitting and risk for obesity.

There are, however, several potential pitfalls with the experimental methods and interpretation of results in the animal studies performed by Jansson et al. (2018). These include use of an extreme diet (60\% of calories from fat) to induce resting weight (mass) gain, a highly invasive method used to artificially increase weight (surgical implantation of unweighted and weighted capsules), absence of no treatment controls, and possible off-target effects of depleting osteocytes using diphtheria toxininduced receptor transgene expression (Al-Jazzar et al. 2016). It is therefore important to challenge this intriguing model using alternative, non-surgical approaches in animals fed less extreme diets.

Because resting weight is the product of mass $x$ acceleration, we investigated the effects of minimally invasive but large magnitude changes in resting weight on body mass in growing rodents. We accomplished this by measuring resting weight following orbital spaceflight (microgravity), hindlimb unloading (simulated microgravity), and centrifugation on Earth (simulated hypergravity) and in orbit (simulated normal gravity). If a gravitostat acts as a physiological regulator of energy balance by sensing changes in resting weight, weightlessness during spaceflight and on lower limbs during hindlimb unloading should result in increased weight and centrifugation at $>1$ G should result in decreased weight. Because surgical implantation of empty and weighted capsules may induce a graded injury response (with loaded capsules more injurious than empty ones), we also investigated whether a non-surgical form of injury (ionizing radiation) duplicates (higher doses more injurious than lower doses) leptin-independent resting weight changes attributed to gravitostat signaling.

\section{Materials and methods}

The Bion 4 and space shuttle experiments were approved by Animal Welfare Committees representing the institutions administering the studies (see publications below). The mouse hindlimb unloading and radiation studies were performed at Oregon State University and the Oregon State University Institutional Animal Care and Use Committee approved the experimental protocols.

\section{Bion 4 flight (microgravity and simulated gravity)}

Cosmos 936 mission on Bion 4 was launched on August 3, 1977 and recovered on August 22, 1977. The details of the flight have been published (Morey-Holton 1978, Spengler et al. 1983). Here we report weight (resting weight at 1 $\mathrm{G}$ is equivalent to mass) determined prior to spaceflight (baseline), following spaceflight, and following recovery from spaceflight. Male Wistar rats from the following treatment groups were studied: ground control, ground centrifuge, omega centrifuge, spaceflight and spaceflight centrifuge. Animals in the flight centrifuge were centrifuged during orbit at $1.0 \mathrm{G}$. The centrifuged ground controls experienced $1.56 \mathrm{G}$, which is perceived as a $56 \%$ increase in body weight. The rats in the omega centrifuge group were located in a vivarium and comprised an additional environmental control for cages used for centrifugation; the omega centrifuge was configured such that the animals perceived a small increase in weight (1.04 G). Stationary and on-centrifuge ( $1.56 \mathrm{G})$ ground controls were housed in cages identical to the flight rats and located in a mock spacecraft subjected to environmental conditions (including noise, acceleration of launch and landing and temperature fluctuations during flight) that closely replicated those experienced by the flight animals. Flight animals were exposed to 18.5 days of microgravity (negligible resting weight) or normal resting weight (spaceflight centrifuge, $1.0 \mathrm{G}$ ). Rats were euthanized a few hours after landing (recovery, $\mathrm{R}+0$ ) or transferred to vivarium housing and euthanized 25 days after landing $(R+25)$. Rats were fed a paste diet with $25 \%$ energy derived from fat $(\sim 1.8 \times$ standard chow diet). The group designations here and in subsequent studies described below conform to those used in prior publications. 


\section{Space shuttle flights (microgravity)}

Resting weights of rats flown on space transport system (STS)-41, STS-52, STS-57 and STS-62 missions and ground controls were obtained through the Center for Cell Research located at the Pennsylvania State University. Weights of rats flown on STS-56 were collected by the senior author prior to euthanasia.

PSE-1 spaceflight mission on STS-41 was launched on October 6, 1990 and recovered on October 10, 1990. The flight details are published (Jiang et al. 1993, Turner 1995). Male Sprague-Dawley rats from three groups were studied: baseline, ground control, and spaceflight. PSE-2 spaceflight mission on STS-52 was launched on March 4, 1994 and recovered on March 18, 1994. The flight details are published (Turner et al. 1995). Male Sprague-Dawley rats from two treatment groups were studied: ground control and spaceflight. PARE-3 spaceflight mission on STS-56 was launched on April 8, 1993, and recovered on April 17, 1993. The flight details are published (Sibonga etal.2000). Male Sprague-Dawley rats from two groups were studied: ground control and spaceflight. PSE-3 spaceflight mission on STS-57 was launched on June 21, 1993 and recovered on July 1, 1993. The flight details are published (Westerlind \& Turner 1995). Male Fischer 344 rats from two groups were studied: ground control and spaceflight. PSE-4 spaceflight mission on STS-62 was launched on March 4, 1994 and recovered on March 18, 1994. The flight details are published (Cavolina et al. 1997). Female Fischer 344 rats from four groups were studied: baseline, ovary-intact ground control, ovariectomized (ovx) ground control, and ovx spaceflight. Rats used in the space shuttle studies consumed a powder diet formulation based on the American Institute of Nutrition (AIN)-76 semi-purified diet in which fat contributed $\sim 11 \%$ of total energy.

\section{Hindlimb unloading (simulated microgravity) in normal and leptin signaling-deficient obese mice}

The method used to hindlimb unload 4-month-old male WBB6F1/J (WT) and WBB6F1/J-Kitw/Kit ${ }^{W-v}\left(K^{W} t^{W / W-v}\right)$ mice is described in detail (Keune et al. 2017). An identical procedure was used to hindlimb unload male C57Bl/6J and leptin-deficient $o b / o b$ mice (Keune et al. 2019).

\section{Radiation (injury) in normal and leptin signaling-deficient obese mice}

Eight-week-old female C57BL/6J (WT) and leptin receptordeficient $d b / d b$ mice on a B6 background were randomized by weight into one of six groups ( $n=3$ /group): untreated WT, irradiated (5 Gy) WT, irradiated (10 Gy) WT, untreated $d b / d b$, irradiated (5 Gy) $d b / d b$, and irradiated (10 Gy) $d b / d b$. Transplant recipients were irradiated using a Co 60 irradiator source (Radiation Center, Oregon State University) and reconstituted, by injection $(200 \mu \mathrm{L})$ in the tail vein, with $1 \times 10^{7}$ donor bone marrow cells isolated from femurs and tibias of WT donor mice as described (Deyhle et al. 2019).

\section{Statistical analysis}

Comparisons of mean body mass following 19 days in orbit or 25 days post-flight for Wistar male rats randomized to ground control, spaceflight, ground centrifuge, omega centrifuge, or spaceflight centrifuge groups were performed by using a linear model containing a distinct mean parameter for each group and common variance. Two-sample t-tests or a nonparametric permutation-based modification of the two-sample multivariate Hotelling's test was used to compare preflight to post-flight mean body mass for ground control and spaceflight groups. Comparisons of mean body mass between baseline, ovary-intact ground controls, ovx ground controls, and ovx spaceflight groups were made using one-way ANOVA. Paired t-tests and one-way ANOVA were used to compare the difference in mass at baseline to after 2 weeks of hindlimb unloading. Comparisons of mean body mass for $\mathrm{C} 57 \mathrm{BL} / 6 \mathrm{~J}$ and $d b / d b$ female mice randomized to a control group or different doses of $\gamma$-radiation (5 Gy and $10 \mathrm{~Gy}$ ) were made using paired t-tests. Model assumptions (normality and equal variance) were assessed numerically using Anderson-Darling and Levene's tests and graphically using boxplots, dotplots, normal quantile plots, and residual plots. $P$-values were adjusted for multiple comparisons by setting the maximum false discovery rate (Benjamini \& Hochberg 1995) to 5\%. Differences were considered significant at $P \leq 0.05$. All data are presented as mean \pm S.E. Data analysis was performed using $\mathrm{R}$ version 3.4.3 (R Core Team 2017).

\section{Results}

\section{Effect of weightlessness resulting from microgravity on resting weight of male Wistar rats}

Gravitostat signaling should result in an increased mass gain in growing rats fed a moderately high-fat diet during microgravity. Figure $1 \mathrm{~A}$ summarizes changes 
A

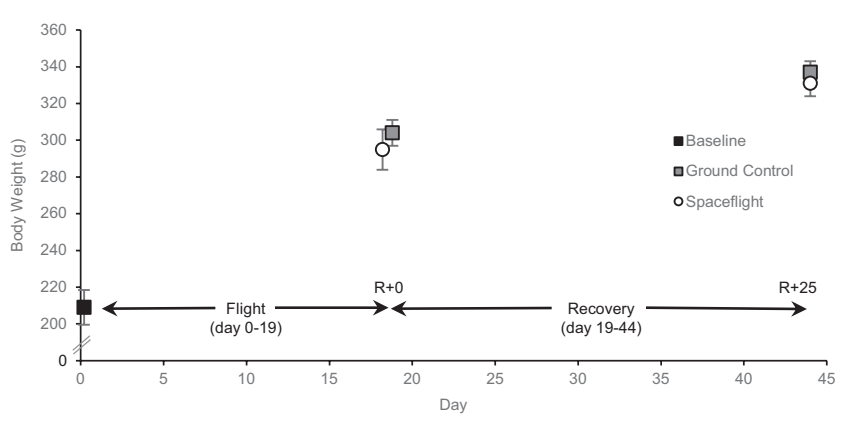

B

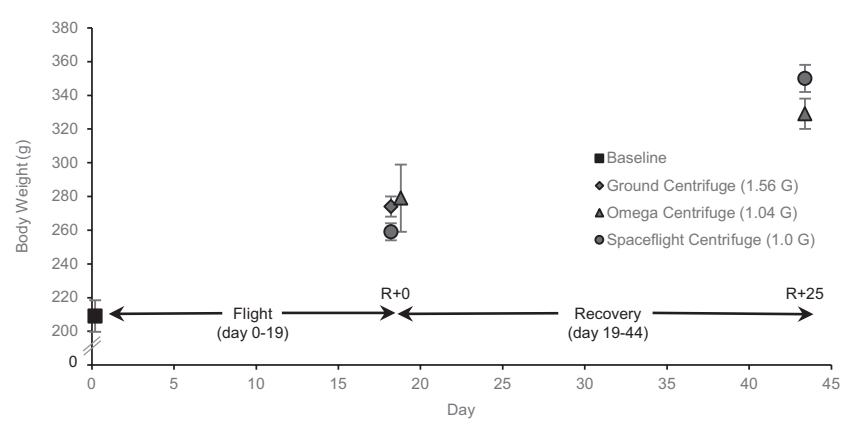

Figure 1

Effects of microgravity (panel A) and simulated gravity (panel B) on resting weight in growing male Wistar rats. Resting weight was measured in a group of rats euthanized at launch (baseline), in flight and ground animals following the 19-day spaceflight $(R+0)$, and in flight and ground animals 25 days following recovery from spaceflight $(R+25)$. Resting weight did not differ $(P>0.05)$ among ground control groups and spaceflight groups at $\mathrm{R}+0$ or $\mathrm{R}+25$. Values are mean \pm S.E., $n=5-10$ /group.

in ground controls and rats flown on the Cosmos 936 mission. Resting weight was measured prior to launch (baseline), following 19 days in orbit $(\mathrm{R}+0)$, and 25 days post-flight $(\mathrm{R}+25)$. Weight was also measured in ground controls housed aboard a mock spacecraft subjected to environmental conditions mimicking those aboard the spacecraft. There were no significant differences in weight between age-matched ground control and flight rats measured prior to launch, at $\mathrm{R}+0$ or at $\mathrm{R}+25$. As such, contrary to prediction, microgravity did not increase body mass compared to $1 \mathrm{G}$.

\section{Effect of increased weight resulting from simulated gravity on resting weight of male Wistar rats}

Gravitostat signaling should result in reduced mass in rats centrifuged at $>1 \mathrm{G}$. Figure $1 \mathrm{~B}$ summarizes resting weight changes among rats centrifuged at $1.04 \mathrm{G}$ on Earth (omega centrifuge), $1.56 \mathrm{G}$ in a mock spacecraft on Earth, and $1.0 \mathrm{G}$ during spaceflight. The inflight-centrifuged rats provided a normal weight $(1.0 \mathrm{G})$ control for environmental factors, such as increased exposure to radiation, unique to spaceflight. Differences in body mass were not detected between rats centrifuged at 1.04 G on Earth (omega centrifuge), $1.56 \mathrm{G}$ on Earth (ground centrifuge), or $1.0 \mathrm{G}$ during spaceflight (spaceflight centrifuge) and euthanized at $\mathrm{R}+0$. The mean weight of rats at $\mathrm{R}+0$ did not differ between animals housed in static cages and animals housed in rotating centrifuge cages. Similarly, differences in resting weight were not detected between rats centrifuged at $1.04 \mathrm{G}$ on Earth and $1.0 \mathrm{G}$ during spaceflight and euthanized at $\mathrm{R}+25$. The mean weight of rats at $\mathrm{R}+25$ did not differ between animals housed in static cages and animals housed in rotating centrifuge cages during flight. As such, contrary to prediction, weight loss was not observed in rats subjected to increased gravity.

\section{Effect of weightlessness resulting from microgravity on resting weight of male Sprague-Dawley and Fischer 344 rats}

While the results of Cosmos 936 (Fig. 1) fail to support gravitostat regulation of body weight, it is plausible that duration of exposure to microgravity and/or factors unique to strain, age, body weight or sex obscured our detection of gravitostat regulation. We, therefore, evaluated resting weight in rats in four additional spaceflight studies (Fig. 2) to address these biological variables. We report weight changes for male Sprague-Dawley rats $(5,5.5$, and 6 weeks old at launch, respectively) exposed to microgravity for 4 days (STS-41, Fig. 2A), 9 days (STS-56, Fig. 2B), or 10 days (STS-52, Fig. 2C). We also report weight changes for male Fischer 344 rats (7-8 weeks old at launch) exposed to microgravity for 10 days (STS-57, Fig. 2D).

Weight was lower in rapidly growing male SpragueDawley rats following the 4-day flight compared to ground controls. However, significant differences in weight were not detected following the 9-day or 10-day flights. Similarly, significant differences in weight were not detected between flight and ground control male Fischer 344 rats following the 10-day flight.

It is plausible that a spaceflight-induced increase in energy expenditure (e.g. due to stress of a novel experience) obscured increased appetite and hyperphagia during flight. However, food consumption was measured on STS-41 (4-day flight) and STS-52 (10-day flight) and did not differ between ground control and flight animals (data not shown). 
A
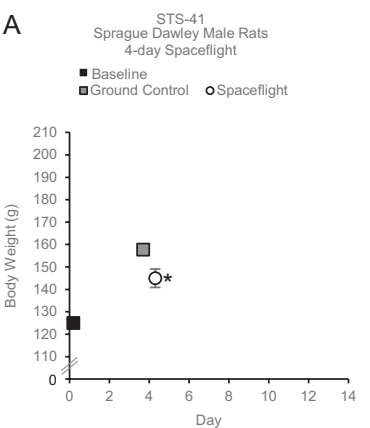

D

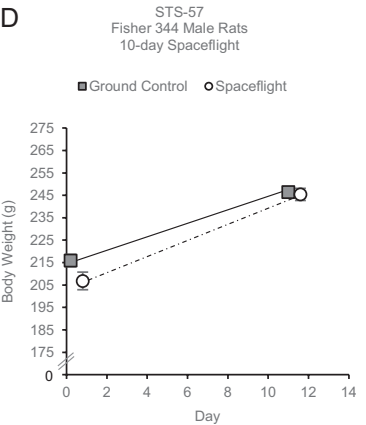

Effect of weightlessness resulting from microgravity on resting weight of female Fischer 344 rats

Few spaceflight missions have flown female rats. A notable exception is STS-62. In this study, slowly growing (12 weeks old at launch) ovx Fischer 344 rats were flown for a duration of 14 days. We utilized weight data from these animals to address the role of the hypothesized gravitostat in limiting body mass gain associated with hyperphagia and reduced energy expenditure induced by acute ovarian hormone withdrawal (Witte et al. 2010). As expected, ovx rats had greater body mass compared to agematched ovary-intact ground controls (Fig. 2E). However, contrary to an expected increase in mass accrual during microgravity predicted by the gravitostat, significant differences in weight were not detected following flight between the ovx ground controls and ovx flight animals.

\section{Effects of simulated microgravity (hindlimb unloading) on resting weight in four strains of male mice, including obese leptin-deficient ob/ob mice}

Conceptually, the gravitostat endeavors to explain the association between duration of sitting and weight gain. Unloading the hindlimbs in a rodent model should therefore interrupt gravitostat signaling in a manner similar to microgravity. However, we have not observed increased weight in hindlimb-unloaded mice or rats (Widrick et al. 2008, Keune et al. 2017). It is possible that a threshold weight is necessary to initiate gravitostat

\section{Figure 2}

Effects of microgravity on resting weight in growing Sprague-Dawley male rats (panels A, B and C), Fischer male rats (panel D), and Fischer ovariectomized (ovx) female rats (panel E). Resting weight was measured in a group of rats euthanized at launch (baseline; panels $\mathrm{A}$ and $\mathrm{E}$ ) or in ground controls and flight animals prior to launch and following flight (panels B, C, and D). Values are mean \pm S.E., $n=6$-12/group. *Different from ground control, $P<0.05$; ** Different from ground control intact, $P<0.05$. regulation (Ohlsson et al. 2018). As such, we evaluated the effect of hindlimb unloading for 2 weeks on body weight in 4-month-old lean and obese mice. The results are shown in Fig. 3. In contrast to an increase in weight predicted by the gravitostat, obese leptin-deficient ob/ob mice (C57BL/6J background) and lean C57BL/6J mice lost weight during hindlimb unloading. Similarly, intermediate-weight $K i t^{W / W-v}$ mice (WBB6F1/J background) and lean WBB6F1/J mice lost weight.

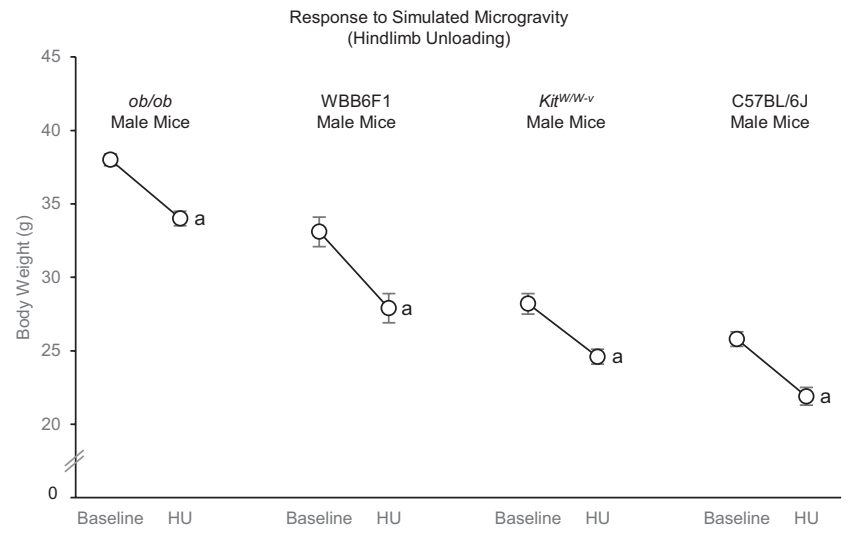

Figure 3

Effects of 14 days of simulated microgravity (hindlimb unloading, HU) on resting weight in four strains of adult (4-month-old) female mice differing in starting weight. Resting weight was measured at baseline (pre-hindlimb unloading) and prior to sacrifice 14 days later. Values are mean \pm S.E., $n=10 /$ group. aDifferent from baseline, $P<0.05$. 


\section{Effects of injury (radiation) on resting weight in two strain of female mice including obese leptin receptor-deficient $\mathrm{db} / \mathrm{db}$ mice}

Based on the results of hindlimb unloading experiments in mice reported here, we pursued the possibility that changes in weight attributed to a gravitostat are due, at least in part, to a non-specific injury response. In the studies conducted by Jansson et al. (2018), body mass was transiently reduced in mice following surgical implantation of an empty capsule into the abdomen and the magnitude of the reduction in biological body mass was increased when mass was added to the capsule. The reduction in biological body mass with the empty capsule is likely due to an injury response. It seems plausible adding additional mass to the implanted capsule could magnify this response, resulting in greater loss of body weight. If this interpretation is correct, it should be possible to replicate weight changes attributed to a gravitostat by graded increases in injury. As a proof of concept, we evaluated two doses of ionizing radiation on resting weight in mice.

Weight changes following exposure of C57BL/6J and leptin receptor-deficient $d b / d b$ female mice on a B6 background to high dose $\gamma$-radiation (5 Gy and 10 Gy) are shown in Fig. 4. Radiation resulted in dose and

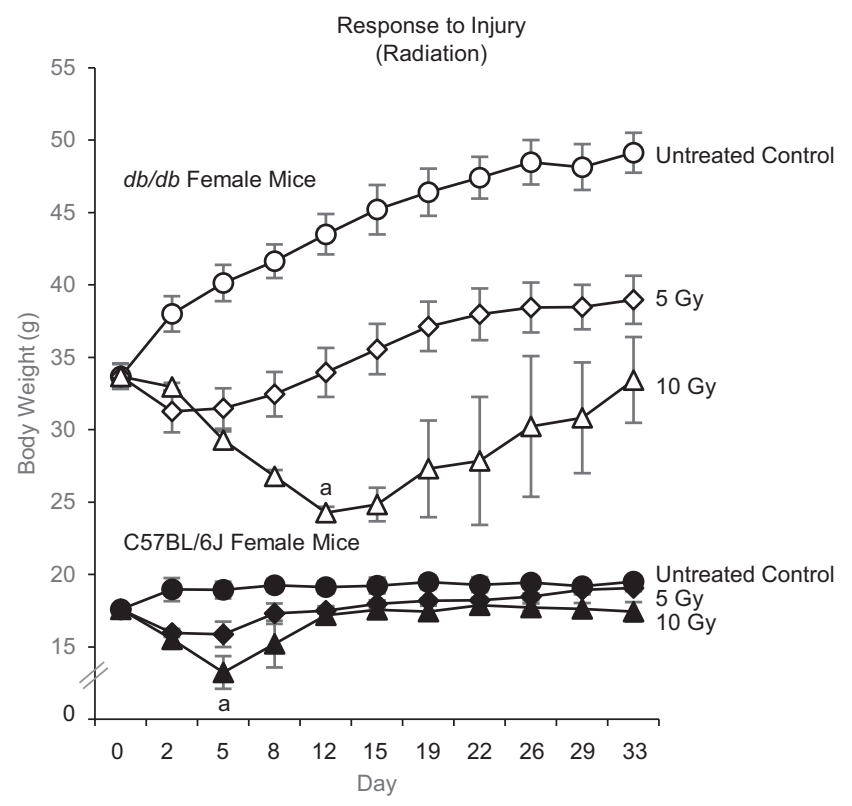

Figure 4

Time course effects of ionizing radiation on resting weight in leptin receptor-deficient $d b / d b$ mice and C57BL/6J mice. Resting weight was measured immediately prior to irradiation and twice/week for 5 weeks subsequently. Values are mean \pm S.E., $n=3$ /group. aMinimum value different from baseline, $P<0.05$.

(c) 2020 Society for Endocrinology Published by Bioscientifica Ltd. Printed in Great Britain strain-dependent reductions in weight followed by near normal weight gain. The acute injury and recovery response pattern was similar between the two strains, but leptin receptor-deficient $d b / d b$ mice experienced a more dramatic reduction in resting weight. At $5 \mathrm{~Gy}$, the mean body weight on day 5 when it reached its minimum for $d b / d b$ mice was $31.5 \mathrm{~g}$ (s.E. $=1.4 \mathrm{~g}$ ). A paired t-test of equal mean weight at baseline and on day 5 has $P$-value $=0.18$. At $10 \mathrm{~Gy}$, the mean body weight on day 12 when it reached its minimum was $24.3 \mathrm{~g}$ (s.e. $=0.4 \mathrm{~g}$ ). A paired t-test of equal mean weight at baseline and on day 12 has $P$-value $=0.0006$. For B6 mice, at $5 \mathrm{~Gy}$, the mean body weight on day 5 when it reached its minimum for B6 mice was $15.9 \mathrm{~g}$ (S.E. $=0.9 \mathrm{~g}$ ). A paired t-test of equal mean weight at baseline and on day 5 has $P$-value $=0.11$. At $10 \mathrm{~Gy}$, the mean body weight on day 5 when it reached its minimum was $13.2 \mathrm{~g}$ (s.E.=1.1 g). A paired t-test of equal mean weight at baseline and on day 12 has $P$-value $=0.012$. Therefore, increasing the dose to 10 Gy resulted in a significant reduction in weight.

Orbital spaceflight results in increased exposure to ionizing radiation. The cumulative radiation dose measured within the spacecraft during Cosmos 936 mission was $\sim 5$ mGy. Thus, an acute dose of radiation (5 Gy), 1000 times greater than cumulative exposure during Cosmos 936, resulted in a relatively modest transient reduction in weight.

\section{Discussion}

Resting weight changes observed during and following the Cosmos 936 mission in rats fed a moderately high-fat diet constitute a rigorous test of the gravitostat hypothesized by Jansson et al. (2018). Specifically, near weightlessness during free fall while in low Earth orbit, normal and increased weight during centrifugation, and transition from these interventions to normal $1.0 \mathrm{G}$ vivarium housing provide non-surgical strategies to establish the effects of physiologically relevant but abrupt changes in weight experienced by the lower limbs on body mass. The hypothesized gravitostat predicts that changes in resting weight in ambulatory animals would result in reciprocal changes in body mass. Contrary to prediction, body mass did not increase in weightless rats or decrease in $\sim 1.6$ G-centrifuged rats compared to their respective normal weight controls. Furthermore, additional spaceflight studies performed in male and ovx female rats and hindlimb unloading studies in lean and obese male mice failed to detect weight changes consistent with gravitostat signaling. In contrast, injury induced by acute exposure 
to high dose ionizing radiation mimicked the weight loss pattern observed following surgical implantation of empty and weighted capsules.

Some studies have identified positive associations between duration of sitting and risk for obesity (Levine et al. 2005, Chau et al. 2012), while other studies suggest that reduced energy expenditure by individuals in developed countries is unlikely to be a major cause for obesity. For example, studies of Hadza hunter-gatherers challenge the concept that Western lifestyles lead to decreased energy expenditure or result in more sitting time (Pontzer et al. 2012). It is also notable that Old Order Amish, a population that exceeds recommended physical activity levels and avoids a Western lifestyle, are not protected from obesity during aging (Hsueh et al. 2000).

The adipokine leptin plays an established role in the regulation of appetite and energy expenditure and there is evidence that leptin resistance contributes to obesity (Jequier 2002). The gravitostat is hypothesized to function as a leptin-independent regulator of appetite that acts physiologically to reduce risk for developing leptin resistance. In this regard, the putative gravitostat is not unique. For example, estrogen is similarly anorectic in leptin-replete WT and leptin-deficient $o b / o b$ mice (Gao et al. 2007). Ovx results in excessive weight gain in rats in spite of increased leptin levels and the weight gain is due to a combination of hyperphagia and reduced energy expenditure (Witte et al. 2010). As expected, ovx ground controls in STS-62 were heavier than age-matched ovary-intact ground controls. Importantly, there was no difference in body weight following spaceflight between the flight ovx and ground control ovx rats. Thus, contrary to the outcome predicted by a gravitostat, microgravity did not accentuate excess weight gain in ovx rats. Further support is provided by studies in humans. Matsumoto et al. (2011) evaluated weight changes in 514 astronauts during spaceflight missions and found that, on average, astronauts lost $\sim 2.1 \%$ of their starting body weight.

Body mass changes attributed to the gravitostat are similar in pattern to those resulting from injury and/or physiological stress. Surgical implantation of capsules and high dose $\gamma$-radiation each result in hypophagia-mediated weight loss secondary to injury and hindlimb unloading results in an acute stress response. The hindlimb unloading model used in the studies reported here has evolved over time, with improvements resulting in lower levels of stress hormones and less pronounced weight loss (Morey et al. 1979, Morey-Holton \& Globus 1998, Porsolt 2000). Injury as well as stress-induced weight loss is magnitudedependent; increasing radiation dose from 5 to 10 Gy resulted in greater loss of resting weight. Taken together, these findings suggest that surgical injury combined with a non-specific stress response associated with adding weight to implanted capsules could account for the body mass changes attributed to a gravitostat.

Studies performed prior to the discovery of leptin identified important effects of adrenal and thyroid hormones on energy balance in leptin-deficient $o b / o b$ mice (Oh \& Kaplan 1994, Okuda \& Romsos 1994, Gettys et al. 1997, Groba et al. 2013). More recently, environmental temperature, particularly in mice, has emerged as an important regulator of appetite and energy balance. Individually caged female mice housed at room temperature $\left(22^{\circ} \mathrm{C}\right)$ consume $40 \%$ more calories than mice housed at thermoneutral $\left(32^{\circ} \mathrm{C}\right)$, potentially conferring resistance to excess weight gain in mice fed normal and moderately high-fat diets (Iwaniec et al. 2016). Mice housed at room temperature and thermoneutral temperature demonstrated nearly identical weight gain, but body composition differed, with the mice at the warmer temperature having higher abdominal white adipose tissue mass and leptin levels. $o b / o b$ mice housed at room temperature demonstrate a similarly elevated energy intake, indicating that this important determinant of appetite does not require leptin (Smith \& Romsos 1984). Finally, in the present studies, weight loss during hindlimb unloading and following acute radiation occurred in WT and genetically obese leptin signaling-deficient mice. The latter finding is concordant with results from a previous study (Ablamunits et al. 2007). Thus, graded increases in injury result in corresponding graded increases in weight loss in mice and this response occurs in normal and genetically obese animals.

Jansson et al. (2018) focused on the effects of surgically implanted weights on weight gain in rodents. Studies performed using weighted vests provide an alternative, noninvasive approach for evaluating the effect of artificial increases in weight in animal models and humans. Six weeks of resistance exercise in 5-month-old male Fischer 344 rats wearing weighted vests (weight of vest gradually increased to $104 \%$ of resting body weight) trained to press levers, facilitating full extension and flexion of the hindlimbs, dramatically increased cancellous bone mass but had negligible effects on body weight (Westerlind et al. 1998). Similarly, 9 weeks of resistance training (weight of vests gradually increased to $65 \%$ of body resting body weight) did not result in loss of body weight predicted by a gravitostat in skeletally mature and aged 12- and 22-month-old Fischer 344 rats (Buhl et al. 2001). The absence of a weight response to this intervention is 
not unique to Fischer 344 rats; resistance training with weighted vests increased cardiovascular function without altering body weight in Wistar rats (Souza et al. 2017).

Increasing mass using a weighted vest should mimic the skeletal loading effects of surgical insertion of weights on energy balance. However, the weighted vests were only worn during exercise, indicating that large but transient increases in resting weight are insufficient to activate signaling by the putative gravitostat. Mechanostat signaling responds to transient changes in strain energy but it is possible that the putative gravitostat signaling requires prolonged increases in static skeletal loading in response to resting weight. In support, wearing a weighted vest (11\% body weight) for $8 \mathrm{~h}$ /day for 3 weeks resulted in a $1.6 \mathrm{Kg}$ decrease in body weight (Ohlsson et al. 2020). However, neither energy intake nor expenditure were carefully evaluated in this short duration study, so it is unclear whether the weight loss was attributable to a gravitostat-mediated decrease in appetite. Furthermore, wearing weighted vests that were gradually increased in mass to maintain resting body weight at pre-weight loss levels for an average of $6.7 \mathrm{~h} /$ day for 22 weeks did not accelerate weight loss or influence body composition in calorically restricted older women with obesity compared to women not wearing weighted vests (Kelleher et al. 2017). In the latter study, both treatment groups of women lost $\sim 11 \%$ of their starting weight. Taken together, neither addition of mass during exercise in adult rodents nor $6.7 \mathrm{~h}$ daily intervals of increased mass in obese women resulted in weight loss.

There are limitations shared by studies reported here and those performed by Jansson et al. (2018). Rodents are quadrupeds whereas humans are bipeds. As such, weight gain could result in more profound increases in skeletal loading in rodent fore or hind limbs, depending upon the distribution of accrued weight (Iwaniec \& Turner 2016, Keune et al. 2019). Peritoneal surgery, with or without weighted capsules in rodents, weighted vests in obese humans, the spaceflight environment, centrifugation, and hindlimb unloading in rodents are each likely to induce an acute stress response leading to transient weight loss. Both series of studies evaluated the effects of large, abrupt changes in resting weight. This may be particularly important because normal weight gain is gradual, allowing for adaptive changes in bone mass and architecture, which would influence strain energy levels perceived by osteocytes (Westerlind et al. 1997). For example, an increase in weight could result in a compensatory increase in bone mass and changes in bone architecture which in turn would result in reduced strain energy levels experienced by individual osteocytes (Westerlind et al. 1997). Furthermore, an increase in weight may not have a proportional effect on osteocytes; it would be necessary to measure or calculate strain to determine change in mechanical strain perceived by osteocytes following implantation of weighed capsules (Iwaniec \& Turner 2016). In addition, most analyses to date have focused on growing rodents. This may be a greater concern for the studies performed by Jansson et al. (2018) because weight loss (but not spaceflight) results in suppression of linear growth in young rodents, which may have an independent effect on subsequent weight accrual (Hermanussen et al. 1996, Sibonga et al. 2000).

In summary, neither decreasing weight to negligible levels during spaceflight nor increasing weight to over $150 \%$ of normal during centrifugation influenced body mass accrual in rats. Additionally, exposure to microgravity did not exaggerate ovx-induced weight gain. The absence of change in body mass during microgravity and artificial gravity compared to $1.0 \mathrm{G}$ controls is consistent with studies demonstrating negligible long-duration effects of weighted vests on body mass in rats and humans. In contrast, injury and chronic stress resulted in leptinindependent, magnitude-dependent weight loss. Taken together, these findings do not support the existence of a gravitostat as an important regulator of energy homeostasis.

\section{Declaration of interest}

The authors declare that there is no conflict of interest that could be perceived as prejudicing the impartiality of the research reported.

\section{Funding}

This work was supported by NASA (80NSSC19K0430 and NNX15AL15G).

\section{References}

Ablamunits V, Weisberg SP, Lemieux JE, Combs TP \& Klebanov S 2007 Reduced adiposity in ob/ob mice following total body irradiation and bone marrow transplantation. Obesity 15 1419-1429. (https://doi. org/10.1038/oby.2007.170)

Al-Jazzar A, Javaheri B, Prideaux M, Boyde A, Scudamore CL, Cherifi C, Hay E, Hopkinson M, Boyd M, Cohen-Solal M, et al. 2016 Dmp1 promoter-driven diphtheria toxin receptor transgene expression directs unforeseen effects in multiple tissues. International Journal of Molecular Sciences 18 29. (https://doi.org/10.3390/ijms18010029) Benjamini Y \& Hochberg Y 1995 Controlling the false discovery rate: a practical and powerful approach to multiple testing. Journal of the Royal Statistical Society: Series B $\mathbf{5 7}$ 289-300. (https://doi. org/10.1111/j.2517-6161.1995.tb02031.x) (c) 2020 Society for Endocrinology Published by Bioscientifica Ltd.
Printed in Great Britain 
Bonewald LF \& Johnson ML 2008 Osteocytes, mechanosensing and Wnt signaling. Bone 42 606-615. (https://doi.org/10.1016/j. bone.2007.12.224)

Buhl KM, Jacobs CR, Turner RT, Evans GL, Farrell PA \& Donahue HJ 2001 Aged bone displays an increased responsiveness to low-intensity resistance exercise. Journal of Applied Physiology 90 1359-1364. (https://doi.org/10.1152/jappl.2001.90.4.1359)

Cavolina JM, Evans GL, Harris SA, Zhang M, Westerlind KC \& Turner RT 1997 The effects of orbital spaceflight on bone histomorphometry and messenger ribonucleic acid levels for bone matrix proteins and skeletal signaling peptides in ovariectomized growing rats. Endocrinology 138 1567-1576. (https://doi.org/10.1210/ endo.138.4.5040)

Chau JY, van der Ploeg HP, Merom D, Chey T \& Bauman AE 2012 Crosssectional associations between occupational and leisure-time sitting, physical activity and obesity in working adults. Preventive Medicine $\mathbf{5 4}$ 195-200. (https://doi.org/10.1016/j.ypmed.2011.12.020)

Deyhle RT, Jr, Wong CP, Martin SA, McDougall MQ, Olson DA, Branscum AJ, Menn SA, Iwaniec UT, Hamby DM \& Turner RT 2019 Maintenance of near normal bone mass and architecture in lethally irradiated female mice following adoptive transfer with as few as 750 purified hematopoietic stem cells. Radiation Research 191 413-427. (https://doi.org/10.1667/RR15164.1)

Forouhi NG, Krauss RM, Taubes G \& Willett W 2018 Dietary fat and cardiometabolic health: evidence, controversies, and consensus for guidance. BMJ 361 k2139. (https://doi.org/10.1136/bmj.k2139)

Frost HM 1987 The mechanostat: a proposed pathogenic mechanism of osteoporoses and the bone mass effects of mechanical and nonmechanical agents. Bone and Mineral 2 73-85.

Gao Q, Mezei G, Nie Y, Rao Y, Choi CS, Bechmann I, Leranth C, ToranAllerand D, Priest CA, Roberts JL, et al. 2007 Anorectic estrogen mimics leptin's effect on the rewiring of melanocortin cells and Stat3 signaling in obese animals. Nature Medicine 13 89-94. (https://doi. org $/ 10.1038 / \mathrm{nm} 1525$ )

Gettys TW, Watson PM, Seger L, Padgett M \& Taylor IL 1997 Adrenalectomy after weaning restores beta3-adrenergic receptor expression in white adipocytes from C57BL/6J-ob/ob mice. Endocrinology 138 2697-2704. (https://doi.org/10.1210/ endo.138.7.5283)

Groba C, Mayerl S, van Mullem AA, Visser TJ, Darras VM, Habenicht AJ \& Heuer H 2013 Hypothyroidism compromises hypothalamic leptin signaling in mice. Molecular Endocrinology 27 586-597. (https://doi. org/10.1210/me.2012-1311)

Hermanussen M, Rol de Lama MA, Romero AP, Ruiz CA, Burmeister J \& Tresguerres JA 1996 Differential catch-up in body weight and bone growth after short-term starvation in rats. Growth Regulation 6 230-237.

Hsueh WC, Mitchell BD, Aburomia R, Pollin T, Sakul H, Gelder Ehm M, Michelsen BK, Wagner MJ, St Jean PL, Knowler WC, et al. 2000 Diabetes in the old order Amish: characterization and heritability analysis of the Amish family diabetes study. Diabetes Care $\mathbf{2 3}$ 595-601. (https://doi.org/10.2337/diacare.23.5.595)

Inoue Y, Qin B, Poti J, Sokol R \& Gordon-Larsen P 2018 Epidemiology of obesity in adults: latest trends. Current Obesity Reports 7 276-288. (https://doi.org/10.1007/s13679-018-0317-8)

Iwaniec UT \& Turner RT 2016 Influence of body weight on bone mass, architecture and turnover. Journal of Endocrinology 230 R115-R130. (https://doi.org/10.1530/JOE-16-0089)

Iwaniec UT, Philbrick KA, Wong CP, Gordon JL, Kahler-Quesada AM, Olson DA, Branscum AJ, Sargent JL, DeMambro VE, Rosen CJ, et al. 2016 Room temperature housing results in premature cancellous bone loss in growing female mice: implications for the mouse as a preclinical model for age-related bone loss. Osteoporosis International 27 3091-3101. (https://doi.org/10.1007/s00198-016-3634-3)

Jansson JO, Palsdottir V, Hagg DA, Schele E, Dickson SL, Anesten F, Bake T, Montelius M, Bellman J, Johansson ME, et al. 2018 Body weight homeostat that regulates fat mass independently of leptin in rats and mice. PNAS 115 427-432. (https://doi.org/10.1073/ pnas.1715687114)

Jequier E 2002 Leptin signaling, adiposity, and energy balance. Annals of the New York Academy of Sciences 967 379-388. (https://doi. org/10.1111/j.1749-6632.2002.tb04293.x)

Jiang B, Roy RR, Navarro C \& Edgerton VR 1993 Absence of a growth hormone effect on rat soleus atrophy during a 4-day spaceflight. Journal of Applied Physiology 74 527-531. (https://doi.org/10.1152/ jappl.1993.74.2.527)

Kelleher JL, Beavers DP, Henderson RM, Yow D, Crotts C, Kiel J, Nicklas BJ \& Beavers KM 2017 Weighted vest use during dietary weight loss on bone health in older adults with obesity. Journal of Osteoporosis and Physical Activity 5 210. (https://doi.org/10.4172/2329. 9509.1000210)

Keune JA, Wong CP, Branscum AJ, Iwaniec UT \& Turner RT 2017 Bone marrow adipose tissue deficiency increases disuse-induced bone loss in male mice. Scientific Reports 7 46325. (https://doi.org/10.1038/ srep46325)

Keune JA, Branscum AJ, Wong CP, Iwaniec UT \& Turner RT 2019 Effect of leptin deficiency on the skeletal response to hindlimb unloading in adult male mice. Scientific Reports 9 9336. (https://doi.org/10.1038/ s41598-019-45587-0)

Levine JA, Lanningham-Foster LM, McCrady SK, Krizan AC, Olson LR, Kane PH, Jensen MD \& Clark MM 2005 Interindividual variation in posture allocation: possible role in human obesity. Science $\mathbf{3 0 7}$ 584-586. (https://doi.org/10.1126/science.1106561)

Matsumoto A, Storch KJ, Stolfi A, Mohler SR, Frey MA \& Stein TP 2011 Weight loss in humans in space. Aviation, Space, and Environmental Medicine 82 615-621. (https://doi.org/10.3357/asem.2792.2011)

Morey ER, Sabelman EE, Turner RT \& Baylink DJ 1979 A new rat model simulating some aspects of space flight. Physiologist 22 S23-S24.

Morey-Holton ER \& Globus RK 1998 Hindlimb unloading of growing rats: a model for predicting skeletal changes during space flight. Bone 22 (Supplement) 83S-88S. (https://doi.org/10.1016/s87563282(98)00019-2)

Morey-Holton ET, Turner RT \& Baylink DJ 1978 Quantitative analysis of selected bone parameters. In Final Report on US Experiments Flown on the Soviet Satellite Cosmos 936, pp. 135-178, Eds SN Rosenzweig \& KA Souza, NASA TM-78526. Washington, DC, USA: NASA.

Oh SS \& Kaplan ML 1994 Early treatment of obese (ob/ob) mice with triiodothyronine increases oxygen consumption and temperature and decreases body fat content. Proceedings of the Society for Experimental Biology and Medicine: Society for Experimental Biology and Medicine 207 260-267. (https://doi.org/10.3181/00379727-207-43814)

Ohlsson C, Hagg DA, Hammarhjelm F, Dalmau Gasull A, Bellman J, Windahl SH, Palsdottir V \& Jansson JO 2018 The gravitostat regulates fat mass in obese male mice while leptin regulates fat mass in lean male mice. Endocrinology 159 2676-2682. (https://doi.org/10.1210/ en.2018-00307)

Ohlsson C, Gidestrand E, Bellman J, Larsson C, Palsdottir V, Hagg D, Jansson PA \& Jansson JO 2020 Increased weight loading reduces body weight and body fat in obese subjects - a proof of concept randomized clinical trial. EClinicalMedicine 22 100338. (https://doi. org/10.1016/j.eclinm.2020.100338)

Okuda T \& Romsos DR 1994 Adrenalectomy suppresses insulin secretion from pancreatic islets of ob/ob mice. International Journal of Obesity and Related Metabolic Disorders 18 801-805.

Pontzer H, Raichlen DA, Wood BM, Mabulla AZ, Racette SB \& Marlowe FW 2012 Hunter-gatherer energetics and human obesity. PLOS ONE 7 e40503. (https://doi.org/10.1371/journal.pone.0040503)

Porsolt RD 2000 Animal models of depression: utility for transgenic research. Reviews in the Neurosciences 11 53-58. (https://doi. org/10.1515/revneuro.2000.11.1.53)

Sibonga JD, Zhang M, Evans GL, Westerlind KC, Cavolina JM, MoreyHolton E \& Turner RT 2000 Effects of spaceflight and simulated https://joe.bioscientifica.com

https://doi.org/10.1530/JOE-20-0393 (c) 2020 Society for Endocrinology Published by Bioscientifica Ltd.
Printed in Great Britain 
weightlessness on longitudinal bone growth. Bone $\mathbf{2 7} 535-540$. (https://doi.org/10.1016/s8756-3282(00)00352-5)

Smith CK \& Romsos DR 1984 Cold acclimation of obese (ob/ob) mice: effects of energy balance. Metabolism: Clinical and Experimental 33 853-857. (https://doi.org/10.1016/0026-0495(84)90114-8)

Souza RR, de Franca E, Madureira D, Pontes CCR, Santana JO \& Caperuto EC 2017 Resistance training improves aortic structure in Wistar rats. Brazilian Journal of Physical Therapy 21 244-250. (https:// doi.org/10.1016/j.bjpt.2017.05.001)

Spengler DM, Morey ER, Carter DR, Turner RT \& Baylink DJ 1983 Effects of spaceflight on structural and material strength of growing bone. Proceedings of the Society for Experimental Biology and Medicine: Society for Experimental Biology and Medicine 174 224-228. (https://doi. org/10.3181/00379727-174-41729)

Stanhope KL 2016 Sugar consumption, metabolic disease and obesity: the state of the controversy. Critical Reviews in Clinical Laboratory Sciences 53 52-67. (https://doi.org/10.3109/10408363.2015.1084990)

Turner RT 1995 Effects of short-term spaceflight and recombinant human growth hormone (rhGH) on bone growth in young rats. Aviation, Space, and Environmental Medicine 66 763-769.

Turner RT, Evans GL \& Wakley GK 1995 Spaceflight results in depressed cancellous bone formation in rat humeri. Aviation, Space, and Environmental Medicine 66 770-774.
Westerlind KC \& Turner RT 1995 The skeletal effects of spaceflight in growing rats: tissue-specific alterations in mRNA levels for TGFbeta. Journal of Bone and Mineral Research 10 843-848. (https://doi. org/10.1002/jbmr.5650100603)

Westerlind KC, Wronski TJ, Ritman EL, Luo ZP, An KN, Bell NH \& Turner RT 1997 Estrogen regulates the rate of bone turnover but bone balance in ovariectomized rats is modulated by prevailing mechanical strain. PNAS 94 4199-4204. (https://doi.org/10.1073/ pnas.94.8.4199)

Westerlind KC, Fluckey JD, Gordon SE, Kraemer WJ, Farrell PA \& Turner RT 1998 Effect of resistance exercise training on cortical and cancellous bone in mature male rats. Journal of Applied Physiology $\mathbf{8 4}$ 459-464. (https://doi.org/10.1152/jappl.1998.84.2.459)

Widrick JJ, Maddalozzo GF, Hu H, Herron JC, Iwaniec UT \& Turner RT 2008 Detrimental effects of reloading recovery on force, shortening velocity, and power of soleus muscles from hindlimb-unloaded rats. American Journal of Physiology: Regulatory, Integrative and Comparative Physiology 295 R1585-R1592. (https://doi.org/10.1152/ ajpregu.00045.2008)

Witte MM, Resuehr D, Chandler AR, Mehle AK \& Overton JM 2010 Female mice and rats exhibit species-specific metabolic and behavioral responses to ovariectomy. General and Comparative Endocrinology 166 520-528. (https://doi.org/10.1016/j.ygcen.2010.01.006)

Received in final form 14 September 2020

Accepted 22 September 2020

Accepted Manuscript published online 23 September 2020
(C) 2020 Society for Endocrinology Published by Bioscientifica Ltd. 